\title{
Performance Evaluation of Internet of Things Prototype for Preeclampsia Monitoring in Antenatal Care
}

\author{
Faith Mueni Musyoka
}

\begin{abstract}
Globally, Preeclampsia has been an alarming condition, thus creating a major concern in its prevention and monitoring. Software developers have implemented several Internet of Things systems to transform human society towards becoming convenient and efficient with maternal health benefits. Due to the freedom in developing these systems, evaluation of the systems' performance must be addressed to enable this revolutionized transformation. Therefore, the study selected an already developed 24-hour ambulatory blood pressure monitoring system for preeclampsia management in antenatal care to represent other IoT systems in conducting the performance evaluation. A sample of fifty pregnant mothers was selected using purposive and simple random sampling to conduct the performance evaluation. The study used a total of 200 blood pressure readings from pregnant mothers. Consistency, response rate, accuracy, reliability, and output were the metrics used to evaluate the IoT based system's performance. During performance evaluation, the study found out that the system achieved all the functionalities expected in its assessment. Therefore, the IoT based system has the potential to inform future antenatal practices.
\end{abstract}

Keywords: Antenatal care, Internet of Things (IoT), Performance Evaluation, Preeclampsia.

\section{INTRODUCTION}

Mo otherhood is a promising and nourishing experience in society, for it focuses on offspring upbringing. However, women's health is well-thought-out as a significant public health concern that influences personal well-being and society's development [1]. According to the World Health Organization (WHO), approximately 830 women die daily from preventable causes related to pregnancy and childbirth. Up to $99 \%$ of these deaths occur in developing countries among women living in rural areas and more impoverished communities [2]. The United Nations (UN) Sustainable Development Goal (SDG) number 3, focusing on good health and well-being, also notes that "maternal mortality levels are currently 14 times higher in developing countries as compared to other regions of the world" [2]. In particular, preeclampsia leads to maternal mortality, fetal mortality, intrauterine growth restriction, and preterm birth [3]. The

Revised Manuscript Received on December 15, 2020.

* Correspondence Author

Faith Mueni Musyoka*, Department of Mathematics, Computing and Information Technology, University of Embu, Embu, Kenya. Email: mueni.faith@embuni.ac.ke

(C) The Authors. Published by Blue Eyes Intelligence Engineering and Sciences Publication (BEIESP). This is an open access article under the CC BY-NC-ND license (http://creativecommons.org/licenses/by-nc-nd/4.0/) term preeclampsia is a condition associated with hypertension, and it commonly starts after the twentieth $\left(20^{\text {th }}\right)$ week of pregnancy [1]. Several studies have shown that preeclampsia is the primary source of fetal complications [4]. Several developed prototypes monitor the blood pressure among the affected. Also, [1] developed a 24-hour ambulatory blood pressure monitoring system for preeclampsia management in antenatal care. The system is a real-time that considers close monitoring of blood pressure in a pregnant mother. The blood pressure reading is from the mothers' wrist using an F1 smart armband [5]. The system then stores the history of the readings, and after that, sends the $\mathrm{BP}$ readings to the family caregiver and health care provider. In case there is an abnormal reading for blood pressure, a mobile application sends a notification. Several studies have shown no cure for the preeclampsia condition other than the baby's birth. Thus, early detection and monitoring contribute significantly to its management and the subsequent prevention of adverse effects [2] [6]. Evaluation is an activity related to data collection on the product's usability that involves a group of users in a specific environment and context [7]. According to [8], during product evaluation, one should define the evaluation's goal, specify the user interface evaluation features, identify the target respondents, and determine the usability metric. The need to evaluate the information systems performances has increased because of a higher requirement of establishing the effectiveness and efficiency of work processes in an organization. According to [9], evaluation of Information System performances means assessing achievements in hardware, software, computer networks, data, and human resources to upgrade and improve in quality of maintenance. The evaluation process includes synthesizing and determining gathered scores to form a common opinion about the evaluated information system's functionality. The functionality, data quality, expected usefulness, expected usage, self-efficiency, usage, influence on individuals, user satisfaction, and organizational factors are vital factors that influence information systems [9]. There are two classes of performance evaluation in the mobile system: analysis of the resource consumption and its influence on applications and the mobile operating system [10]. According to [11], metrics are criteria used to compare the performance using three parameters: Response time, CPU time, and Memory usage. This study aimed to conduct a performance evaluation for the Internet of Things Prototype for preeclampsia monitoring in antenatal care.

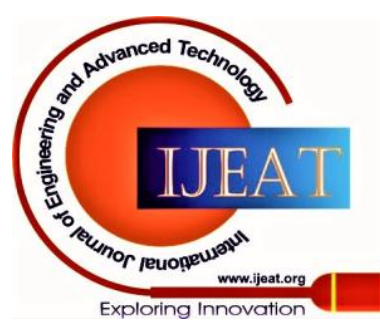


Therefore, in this research, the F1 Smart Bracelet developed by [5] was used to collect the blood pressure readings from the pregnant mother. Also, the developed 24-hour ambulatory blood pressure monitoring system for preeclampsia management in antenatal care by [1] was used as a representative of IoT based prototypes to help in conducting performance evaluation.

Several studies have performed acceptance and usability evaluations of mobile application and cloud-based systems. These studies have examined whether the implemented systems could work as expected in terms of content richness, perceived ease of use, perceived usefulness, and user satisfaction [1]. However, upcoming technologies for reading blood pressure have several features; therefore, there is a need to perform a performance evaluation to examine how the system performed [12]. These led to the author's motivation to begin research work related to the performance evaluation of the IoT prototype in preeclampsia monitoring due to the high mortality experienced in expectant mothers and long-term health complications in developing countries. The article is organized in the following structure. The Materials and Methods section includes the performance evaluation conducted in the IoT system and the research design used in the research. The Results section presents the outcomes. The Discussion section describes the significance of the results obtained, and the Conclusion section provides a summary.

\section{MATERIALS AND METHODS}

Performance evaluation of Information Technologies is an essential task for it leverages the benefits of the technologies [13]. Thus, mobile app developers need to know about the mobile application's performance after developing a sustainable mobile application quality. Using a 24-hour ambulatory blood pressure monitoring system for preeclampsia management in antenatal care by [1], The study conducted performance evaluation to confirm that the prototype worked as expected to satisfy user needs, which in this case is preeclampsia monitoring. The participants involved in the study were 50 from two Counties: Kiambu and Embu, both from Kenya, in Thika level 5 hospital, and Embu level 5 hospital, respectively. The study selected expectant mothers who came for antenatal care and had more than 20 weeks of gestation. The choice of selecting the pregnancy stage was because the diagnosis of hypertension disorders occurs from the second semester of pregnancy period [1]. During data collection, each participant had to wear the F1 smart armband for four hours and taking the blood pressure reading within a one-hour interval. Therefore, a total of 200 $\mathrm{BP}$ readings used to evaluate the performance were retrieved from the 24-hour ambulatory blood pressure monitoring system for preeclampsia management in antenatal care [1]. All users, pregnant mothers, health care providers, and family caregivers registered and logged into the mobile app. The mobile application, cloud database, and electronic BP system used in the hospitals were the integrated components that collected results to evaluate the IoT performance model. Fig 1. shows the flow of the expectant mother's details adopted from [1]. System consistency was measured by taking two BP readings from the same pregnant mother within the same sitting to see the variation between the BP readings. In measuring the consistency indicator, fifteen users' BP readings were taken twice, one after the other, from each pregnant mother. The response rate performance indicator computed the time difference between the BP reading from pregnant mothers' device and the time the message got to the health care provider/family caregiver. A sample test of twenty expectant mothers computed the response rate. The system accuracy indicator compared the same pregnant mother's BP readings using the proposed IoT system and those obtained from the electronic hospital device (Omron System). Twenty-one expectant mothers were used to collect data from both the F1 smart armband device and Omron System to test accuracy. The system reliability performance indicator computed the percentage error rate produced during $\mathrm{BP}$ readings. The output is a performance indicator that showed the system made a notification to a family member, doctor, and pregnant mother when BP is above standard.

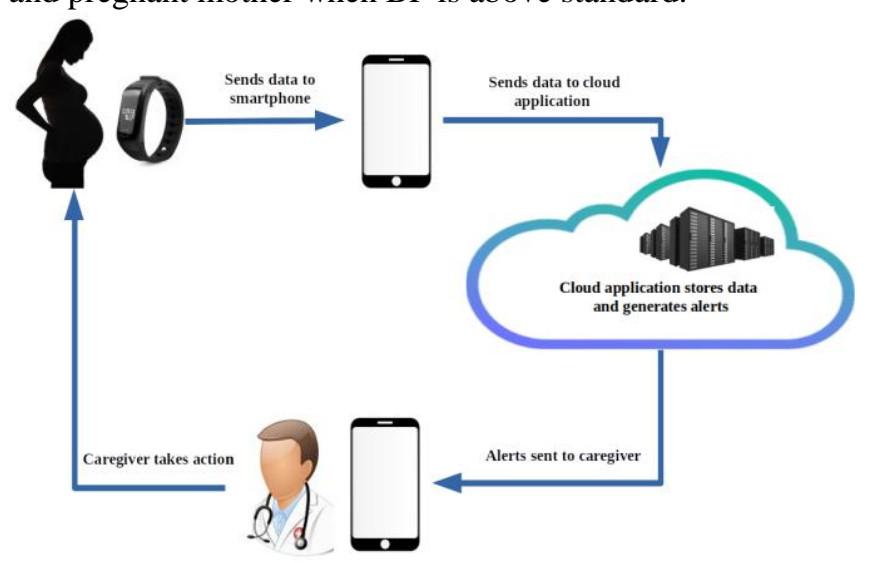

Fig. 1. A 24 Hour Ambulatory BP monitoring system architecture[1]

\section{RESULTS}

The performance metrics used for the study were analyzed as follows:

\section{A. Consistency}

It was found out that the blood pressure systole reading for test 1 and test 2 using the same Smart armband device and the mother sitting in the same position was strongly and positively correlated $(r=0.906, p<0.000)$ (Table 1$)$. The diastole reading for test 1 and test 2 using the same Smart armband device and the mother sitting in the same position was strongly and positively correlated $(r=0.793, p<0.000)$, implying that both the blood pressure measurements collected simultaneously were consistent. On systole reading for test 1 and test 2 using the same Smart armband devices and mother sitting in the same position, there was no significant average difference between the two readings $\left(\mathrm{t}_{14}=-1.131, \mathrm{p}<0.277\right)$. On diastole reading for test 1 and test 2 using the same Smart armband devices and mother sitting in the same position, there was no significant average difference between the two readings $\left(\mathrm{t}_{14}=0.603, \mathrm{p}<0.556\right)$. The test seemed logical because the two $\mathrm{BP}$ readings were similar. On average, test 1 systole reading was less than test 2 systole by 1.067 readings (95\% CI [-3.090, 0.957].

\section{Published By:}

Blue Eyes Intelligence Engineering and Sciences Publication

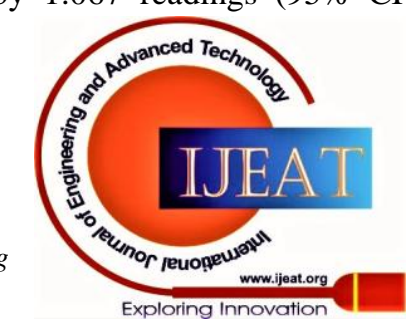


Test 1 diastole readings were more than test 2 diastole by 0.600 readings $(95 \%$ CI $[-1.532,2.732]$. The difference between the tests was extremely minimal, and thus the smart armband system produced consistent results. However, the readings may vary since blood pressure is a hemodynamic

phenomenon influenced by many factors, not least the circumstances of measurement itself, no matter the device used to measure the blood pressure [14].

Table-I: Consistency performance Test

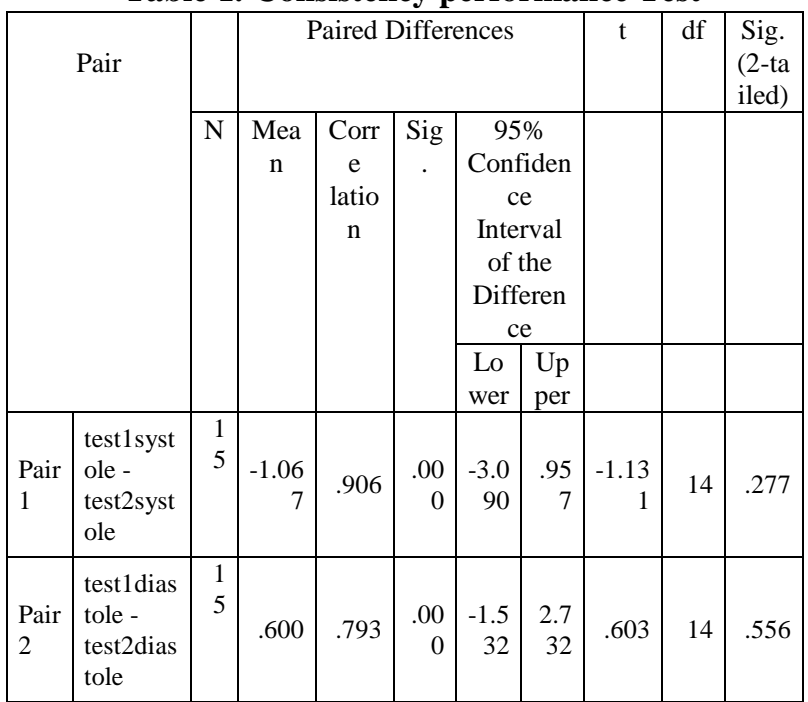

\section{B. Response Rate}

The study showed that the minimum time taken for the blood pressure to reach the health care provider was 3 seconds, while the maximum time taken was 22 seconds, as shown in Table 2 . The mean for the 20 samples taken was 12 seconds. On average, the BP measurements transfer from the smart armband to the smartphone takes less than a minute. Therefore, the device's response rate is high and can measure blood pressure since it produces real-time data without prolonged delay.

Table-II: Descriptive Statistics for Response Time

\begin{tabular}{|l|c|c|c|c|c|}
\hline & N & Min & Max & Mean & Std. Dev \\
\hline $\begin{array}{l}\text { Time } \\
\text { difference }\end{array}$ & 20 & $0: 00: 03$ & $0: 00: 22$ & $0: 00: 12$ & $0: 00: 05$ \\
\hline Valid N & & & & & \\
\hline
\end{tabular}

\section{Accuracy}

The study found out that the blood pressure systole reading for Manual and Smart armband devices was strongly and positively correlated $(\mathrm{r}=0 . .903, \mathrm{p}<0.000)$. The diastole reading for Manual and Smart armband devices was strongly and positively correlated $(\mathrm{r}=0.889, \mathrm{p}<0.000)$. These results imply that both Blood pressure measurements for the two devices were logical and consistent. The readings were related and accurate, where a manual system was used as the control device.

There was no significant average difference between the two systole readings $\left(\mathrm{t}_{20}=-0.984, \mathrm{p}<0.337\right)$ of manual and smart armband devices. There was no significant average difference between the two diastole readings $\left(t_{20}=1.548\right.$, $\mathrm{p}<0.137$ ) of manual and smart armband devices since they both gave almost the same BP readings, which seemed logical.

On average, the manual systole readings were less than the smart band systole by 0.762 readings (95\% CI $[-2.377$, 0.853]. The manual diastole readings were more than the smart band systole by 0.952 readings (95\% CI [-0.331, 2.236]. The difference was extremely minimal, and thus the smart armband system is also accurate compared to the manual device.

Table-III: Accuracy paired sample data

\begin{tabular}{|c|c|c|c|c|c|c|c|c|c|c|}
\hline \multirow{3}{*}{\multicolumn{2}{|c|}{ Pair }} & & \multicolumn{5}{|c|}{ Paired Differences } & \multirow[t]{3}{*}{$\mathrm{T}$} & \multirow[t]{3}{*}{$\mathrm{df}$} & \multirow{2}{*}{$\begin{array}{l}\text { Sig. } \\
\text { (2-ta } \\
\text { iled) } \\
\end{array}$} \\
\hline & & \multirow[t]{2}{*}{$\mathrm{N}$} & \multirow[t]{2}{*}{$\begin{array}{c}\text { Mea } \\
\mathrm{n}\end{array}$} & \multirow[t]{2}{*}{$\begin{array}{c}\text { Corr } \\
\text { elati } \\
\text { on }\end{array}$} & \multirow[t]{2}{*}{$\begin{array}{c}\text { Sig } \\
\text {. }\end{array}$} & \multicolumn{2}{|c|}{$\begin{array}{c}95 \% \\
\text { Confidence } \\
\text { Interval of } \\
\text { the } \\
\text { Difference }\end{array}$} & & & \\
\hline & & & & & & $\begin{array}{c}\text { Low } \\
\text { er }\end{array}$ & $\begin{array}{c}\text { Upp } \\
\text { er }\end{array}$ & & & \\
\hline $\begin{array}{l}\text { Pair } \\
1\end{array}$ & \begin{tabular}{|l|} 
Manual \\
systole-- \\
smartband \\
systole
\end{tabular} & 21 & $\begin{array}{r}-.76 \\
2\end{array}$ & .903 & $\begin{array}{r}.00 \\
0\end{array}$ & $\begin{array}{r}-2.37 \\
7\end{array}$ & .853 & -.984 & 20 & .337 \\
\hline $\begin{array}{l}\text { Pair } \\
2\end{array}$ & $\begin{array}{l}\text { Manual } \\
\text { diastole - } \\
\text { smartband } \\
\text { diastole }\end{array}$ & 21 & .952 & .889 & $\begin{array}{r}.00 \\
0\end{array}$ & -.331 & $\begin{array}{r}2.23 \\
6\end{array}$ & $\begin{array}{r}1.54 \\
8\end{array}$ & 20 & .137 \\
\hline
\end{tabular}

\section{Reliability}

Out of the 218 readings, 12 readings showed zero readings. The error rate was 5.5\%, and the logical BP readings showed $94.5 \%$, as depicted in Table 4 . The smart armband was reliable with the minimal error rate percentage, which could have been caused by external factors such as the disconnecting of smartphones from the Internet.

Table-IV: Reliability performance indicator

\begin{tabular}{|c|l|l|l|}
\hline Value Number & Frequency & Percent (\%) \\
\hline \multirow{3}{*}{} & Value with zero & 12 & 5.5 \\
\cline { 2 - 4 } & $\begin{array}{l}\text { A value greater } \\
\text { than zero }\end{array}$ & 206 & 94.5 \\
\cline { 2 - 4 } & Total & 218 & 100.0 \\
\hline
\end{tabular}

\section{E. Output}

All the 218 readings did not exceed the standard blood pressure and were sent to the allocated health care providers and allocated family caregivers, as presented in Table 5. The system produced the required output and operated as required to send readings to both users.

\section{DISCUSSION}

The study evaluated the performance of the IoT based model for preeclampsia monitoring in antenatal care. The components used in the study were: the 24-hour ambulatory blood pressure monitoring system [1], F1 smart armband [5], and mobile applications installed in the participants' mobile phones. System evaluation is considered a vital activity since system performances influence any information system's success or failure [15]. In the evaluation, five performance metrics were used: consistency, response rate, accuracy, reliability, and output. The F1 smart armband resulted as consistent, 
whereby two BP readings were taken from the same mother sitting in the same position. The difference between the tests was extremely minimal; thus, the smart armband system produced consistent results. The device's response rate was high. The average mean for the time from the smart armband and the time the provider received was 12 seconds.

Thus, there was no prolonged delay in the BP measurements. The device was accurate when compared to the Omron System used in the two hospitals. The BP measurements for the two devices were related and showed to be accurate.

The manual system (Omron System) acted as the control device. Besides, the F1 smart armband was reliable with a minimal error rate percentage of $5.5 \%$, which was caused by external factors such as the disconnecting of smartphones from the Internet. The smart armband produced all the collected BP readings from pregnant mothers and was delivered to the health care providers and family caregivers. The performance metrics proved that the F1 smart armband could be used in hospitals to measure blood pressure. With the use of IoT based model prototype in hospitals, there is distributing BP readings in several health care providers and family caregivers without the challenge of proximity and data delay/loss challenges.

\section{CONCLUSION}

The IoT prototype's evaluation has shown pronounced impedance for Preeclampsia monitoring in antenatal care, especially in developing countries given the prototype's consistency, high response rate, and giving expected output. In conclusion, the integration of F1 smart armband and the 24-hour ambulatory system is a potential IoT system that can work in healthcare to read blood pressure and share data with health care providers and family caregivers. The IoT system can inform antenatal practice in the future without the challenge of proximity and data loss challenges in monitoring preeclampsia among expectant mothers.

\section{ACKNOWLEDGMENT}

The author acknowledges the invaluable contributions of expectant mothers who volunteered to participate in the study. The author also appreciates the Embu Level 5 hospital and Thika Level 5 hospital staff, who authorized system testing and data collection in their respective premises.

\section{REFERENCES}

1. F. M. Musyoka, M. Thiga, and G. Muketha, "A 24-hour ambulatory blood pressure monitoring system for preeclampsia management in antenatal care," Inform. Med. Unlocked, vol. 16, 2019, doi: 10.1016/j.imu.2019.100199.

2. WHO, "Maternal Health.” 2019, Accessed: Feb. 24, 2019. [Online]. Available:

https://www.who.int/news-room/fact-sheets/detail/maternal-mortality.

3. C. Macdonald-Wallis et al., "Antenatal blood pressure for prediction of pre-eclampsia, preterm birth, and small for gestational age babies: development and validation in two general population cohorts," $\mathrm{Br}$. Med. $\quad$ J., 2015, [Online]. Available: https://doi.org/10.1136/bmj.h5948.

4. H. Suhasini and V. Sudarshini, "ARM Based Wearable Device for Blood Pressure,Weight and Temperature Measurement in Pregnant Woman," Int. J. Mag. Eng. Technol. Manag. Res., vol. 2, no. 6, pp. 231-239, Jun. 2015.

5. Desay Information Technology, "F1 Smart Bracelet." Desay Information Technology Co., Ltd, 2019, [Online]. Available:
https://www.smartwatchspecifications.com/Device/f1-blood-pressureoximeter-heart-rate-monitor/.

6. P. . Modesti, A. Perruolo, and G. Parati, "Need for Better Blood Pressure Measurement in Developing Countries to Improve Prevention of Cardiovascular Disease," J. Epidiemology, vol. 25, no. 2, pp. 91-98, 2015.

7. R. Yvonne, H. Sharp, J. Preece, D. Benyon, S. Holland, and T. Carey, Human-Computer Interaction. Essex: Addison Wesley Longman Ltd, 1994.

8. J. Nielsen, Usability Engineering. Boston: MA academic Press, 1993.

9. P. B. Gordana, "Methodological Approaches to Evaluation of Information System Functionality Performances and Importance of Successfulness Factors Analysis,” Manag. Inf. Syst., vol. 4, no. 2, pp. 11-17, 2009.

10. H. Kim, N. Agrawal, and C. Ungureanu, "Examining storage performance on mobile devices," Proc. 3rd ACM SOSP Workshop Netw. Syst. Appl. Mob. Handhelds - MobiHeld, vol. 11, pp. 1-6, 2011.

11. F. Thiago, C. Erika, and A. Moreira, "Performance Evaluation of Android Applications: a Case Study.” PPGC - Institute of Informatics UFRGS, Brazil, 2018.

12. F. M. Musyoka, M. Thiga, and G. Muketha, "An Assessment of Suitable and Affordable Smart armband for preeclampsia Management in Antenatal Care," Int. J. Inf. Technol., vol. 3, no. 6, Jun. 2019.

13. S. Vijaya and H. Sarojadevi, "Performance Evaluation of Cloud and Mobile Application,” Int. Res. J. Eng. Technol., vol. 5, no. 5, pp. 2874-2979, May 2018.

14. G. Beevers, G. Lip, and E. O’Brien, "Blood pressure measurement Part I-Sphygmomanometry: factors common to all techniques," BMJ, vol. 322, pp. 981-985, 2001.

15. N. Balaban, Z. Ristic, J. Durkovic, J. Trninic, and P. Tumbas, "Information technologies and Information Systems," Univ. Econ. Subot., 2006.

\section{AUTHOR PROFILE}

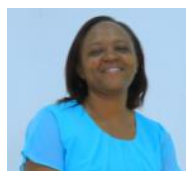

Faith Mueni Musyoka is a Lecturer of Information Technology in the Department of Mathematics, Computing \& Information Technology at University of Embu, Kenya. She holds a Ph.D. in Information Technology from Kabarak University, Msc. in Information Technology and Bsc. Computer Science both from Masinde Muliro University of Science and Technology. She has presented papers in scientific conferences and has publications in refereed journals. Her research interests include Health Informatics, Software Quality, software Metrics, and Internet of Things technologies. She is a Professional Member of ACM.

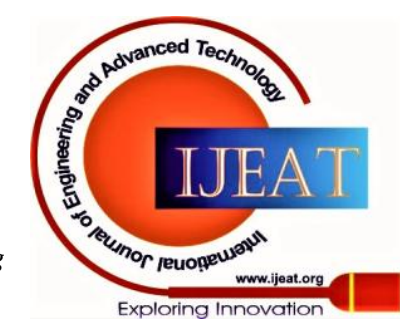

